\title{
Non-fistulous urinary leakage among women attending a Nigerian family planning clinic
}

This article was published in the following Dove Press journal:

International Journal of Women's Health

9 December 201I

Number of times this article has been viewed

Munir'deen A ljaiya'

Hadijat O Raji'

Abiodun P Aboyeji'

Kike T Adesina'

Idowu O Adebara ${ }^{2}$

Grace G Ezeoke'

'Department of Obstetrics and Gynaecology, University of Ilorin Teaching Hospital, Ilorin, Nigeria; ${ }^{2}$ Department of Obstetrics and Gynaecology, Federal Medical

Centre, Ido-Ekiti, Nigeria

Video abstract

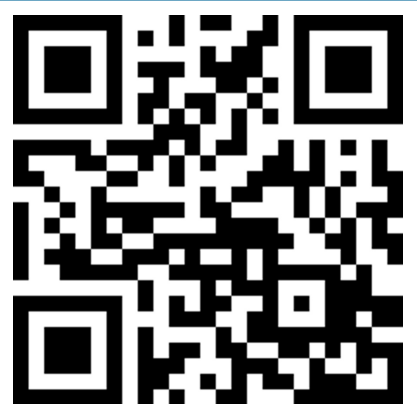

Point your SmartPhone at the code above. If you have a QR code reader the video abstract will appear. Or use: http://dvpr.es/liaiya

Correspondence: Munir'deen A ljaiya Department of Obstetrics and Gynaecology, University of llorin Teaching Hospital, PMB I339, Ilorin, Nigeria

Tel +234803380I565

Email munirijaiya@yahoo.com
Abstract: Urinary leakage is an important gynecological challenge, which has a substantial impact on quality of life. The aim of this study was to determine the prevalence and types of non-fistulous urinary leakage among women attending the family planning clinic of the University of Ilorin teaching hospital, Ilorin, Nigeria. The study was a cross-sectional study carried out between January 3 and April 25 2009. One hundred and two women experienced urinary leakage out of 333 women interviewed, giving a prevalence rate of $30.6 \%$. Stress incontinence was the most common urinary leakage (prevalence rate $12.0 \%$ ). This is followed by urge incontinence (10.8\%), urinary incontinence (4.8\%), and overflow incontinence $(3.0 \%)$. None of the women afflicted sought medical help. Conclusively, this study has demonstrated that non-fistulous urinary leakage is a common problem among women of reproductive age in this environment.

Keywords: non-fistulous urinary leakage, family planning, women, prevalence, types

\section{Introduction}

To a majority of people in developing countries, leakage of urine will usually refer to vesicovaginal fistula because of its high prevalence, ${ }^{1-4}$ whereas in Western countries urinary incontinence, urge incontinence, and genuine stress incontinence will easily come to mind. It is not that the latter conditions do not exist in Nigeria, but people do not consider them as problems that warrant hospital consultation.

The prevalence of urinary leakage was 39\% in a survey conducted in Stockholm, which examined the influence of physical activity and micturition habits on urinary leakage in women before their first pregnancy. ${ }^{5}$ Adult women in European countries had a prevalence rate of $35 \% .{ }^{6}$ Stress incontinence is the most common type of urinary leakage $^{7}$ and the prevalence is higher in white than in black women. ${ }^{8}$

Urinary leakage is an important gynecological condition, which has a substantial impact on quality of life. It is a significant cause of disability and dependence. ${ }^{5}$ Many urinary incontinence cases go unaided. ${ }^{6}$ However, interest and research in non-fistulous urinary leakage receives little or no attention in Nigeria presently. Therefore, this study was designed to determine the prevalence and types of non-fistulous urinary leakage among healthy clients of the family planning clinic of the University of Ilorin teaching hospital, Ilorin, Nigeria.

\section{Methods}

The study was a cross-sectional study carried out in the family planning clinic of the University of Ilorin teaching hospital between January 3 and April 25, 2009. 
Women that visited the clinic during the study period answered the pre-tested questionnaire (see Appendix). The ethical committee of the University of Ilorin teaching hospital approved the study.

Fisher's formula was used for sample size estimation, ${ }^{9}$ and the calculated sample size was 333. The interviewers were female interns in the Department of Obstetrics and Gynecology. Interviewing techniques, eligibility of respondents, and detail of questions were included in the training of the interviewers.

Both books ${ }^{10}$ and some published studies ${ }^{5,11}$ on urinary leakage were sources of the information in the questionnaire. The information included age, parity, mode of deliveries, occupation, involvement in heavy load lifting (a load that needs an assistant to get the load on the person's head), types of symptoms of urinary leakage, and whether they visited any health facility for management. Included in the study were all the women that came to the family planning clinic for contraception during the study period except postnatal women or those with vesicovaginal fistula. Women with vesicovaginal fistula received care at the fistula clinic, which is part of the gynecological clinic.

Definitions of terms used in this study are as follows:

- Urinary leakage: the woman has experienced leakage of urine in the past.

- Urinary incontinence: the woman has involuntary loss of urine that has become a social or hygienic problem.

- Stress incontinence: the woman has experienced leakage of urine on coughing, sneezing, lifting, or exercise.

- Urge incontinence: the woman has a desire to void, but leaks urine before getting to the toilet.

- Overflow incontinence: leakage of urine following urinary retention. ${ }^{5}$

SPSS statistical package (v 17; IBM, Armonk, NY) was used for data analysis. Pearson's $\chi^{2}$ test was used to test significance and $P$ values $<0.05$ were regarded as significant.

\section{Results}

Three hundred and thirty-three eligible respondents' questionnaires were analyzed. One hundred and two women experienced urinary leakage giving a prevalence rate of $30.6 \%$. The age of the women who experienced urinary leakage ranged between 30 and 51 years with a mean of 37.4 years \pm 4.1 (SD). Their parity ranged between 0 and 9 with mean parity $4.1 \mathrm{SD} \pm 1.8$. Figure 1 shows the prevalence of the various types of urinary leakage. Stress incontinence was the most common type with 40 women (prevalence

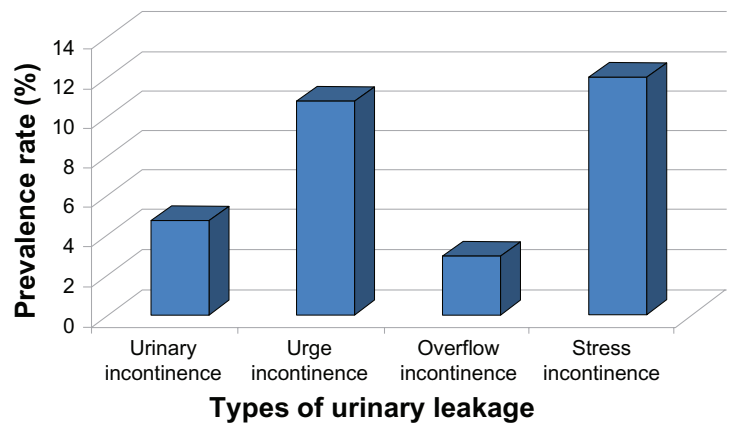

Figure I Types of urinary leakage.

rate [PR]: $12.0 \%$ ) followed closely by urge incontinence with 36 women (PR: 10.8\%). Sixteen women (PR: $4.8 \%$ ) and ten women (PR: $3.0 \%$ ) had experienced symptoms of urinary incontinence and overflow incontinence, respectively.

Figure 2 shows the types of urinary leakage by age. The majority of women with urinary leakage - $63-(61.8 \%)$ were in the age group 30-39 years. The peak age group was 35-39 years in all types of urinary leakage, except in urge incontinence which was between 30-34 years. There was a general dip following these peaks in the age group 40-44 years, before the second rise. The difference in age distribution is significant only for urinary incontinence $(P=0.013)$.

Women who experienced urinary incontinence had the least mean age of 36 years \pm 7.4 and parity $3.8 \pm 2.5$, while women with symptoms of overflow incontinence had the highest mean age of 38.5 years \pm 5.6 and parity $4.4 \pm 1.3$. The difference in parity distribution was significant in only urinary incontinence $(P=0.00)$ and stress incontinence $(P=0.032)$. Figure 3 shows the types of urinary leakage by parity. Ninety-one of the women (89.2\%) suffering from urinary leakage had three or more children, and this is applicable to all types of urinary leakage.

Eighty-eight (86.3\%) women who experienced urinary leakage had a vaginal delivery in their previous deliveries. The difference in the mode of delivery and occurrence of urinary leakage was not statistically significant in all types of urinary leakage except in urinary incontinence $(P=0.001)$. The frequency of women who carried heavy loads and experienced urge incontinence and overflow incontinence symptoms was significantly higher than those who did not carry heavy loads ( $P=0.003$ and $P=0.034$, respectively; see Table 1). None of the affected women visited a health facility for management.

\section{Discussion}

The prevalence of urinary leakage and urinary incontinence varies widely from center to center partly due to differences 




Figure $\mathbf{2}$ Types of urinary leakage by age group.

in the definitions employed in the studies. ${ }^{12}$ In this series, the prevalence of urinary leakage was $30.6 \%$. This is comparable to $35 \%, 39 \%$, and $41 \%$ reported by Hunskaar et al's study involving four European countries, ${ }^{13}$ Eliasson et al in Stockholm, Sweden; ${ }^{5}$ and Jolleys in Leicestershire, $\mathrm{UK}^{14}$ respectively. This prevalence is far less than the $58 \%$ reported by Burgio et al in Pennsylvania, US. ${ }^{15}$ In addition, the reason for a lower prevalence rate among these women may be similar to the findings found among the African American women. African American women have smaller bladder capacities, smaller maximum cystometric capacities, and higher maximum urethral closure pressures compared to Caucasians. ${ }^{16}$ Urodynamic studies will be necessary on these women to validate this assumption. It is worth noting that the wrong diagnosis could occur in up to $25 \%$ of cases, when symptoms alone are considered ${ }^{15}$ as in this study.

The prevalence sequence of the types of urinary leakage experienced in this center is comparable with Shaw et al's multicenter finding in the UK, where stress incontinence was the most common type, followed by urge incontinence. ${ }^{6}$ Stress incontinence was also the most common urinary leakage in the Hunskaar et al finding. ${ }^{13}$

The prevalence of stress incontinence was highest in all age groups of women who complained of urine leakage in this study. The Hunskaar et al findings supported this observation. ${ }^{13}$ In this series, the peak age group was 30-39 years, which is in contrast to other studies. Peak age is around menopause in other studies. ${ }^{6,13,17,18}$ The lower peak age recorded is probably due to the study population, which used women of reproductive age. The cause of the decrease in the prevalence of urinary leakage in the age group 40-44 years, in all types of urinary leakage, is unclear.

The risk of developing urinary incontinence is greater in women with high parity than in women with low parity in this series. Other researchers supported this finding. ${ }^{14,19}$ The mode
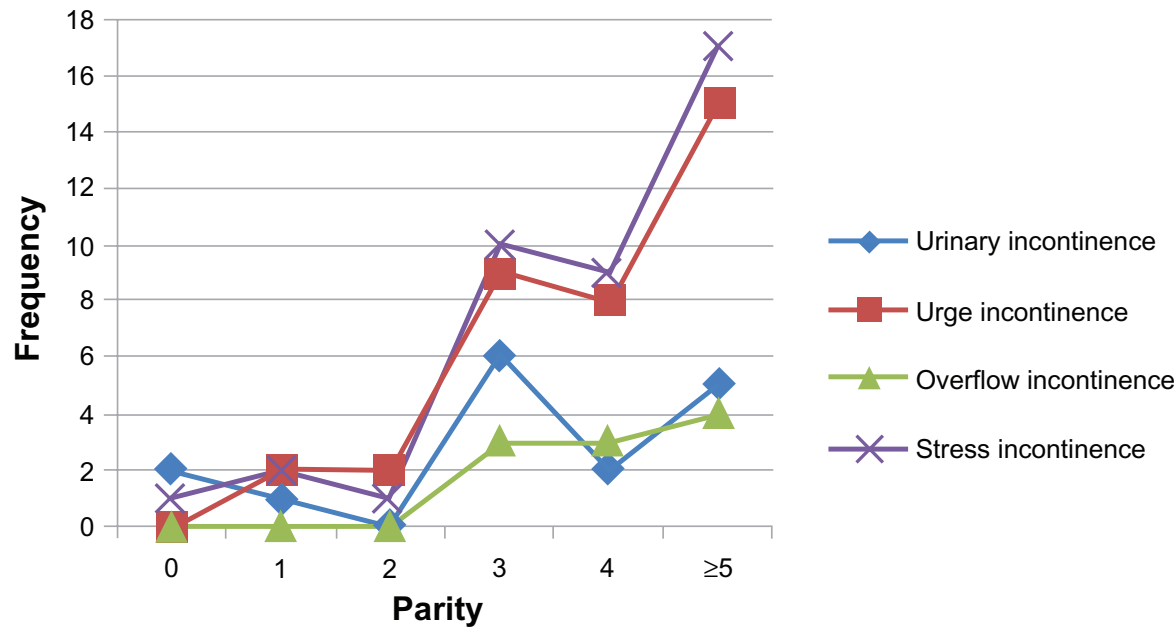

Figure 3 Types of urinary leakage by parity. 
Table I Risk factors against types of urinary leakage

\begin{tabular}{lllll}
\hline Variables & Urinary incontinence & Urge incontinence & Overflow incontinence & Genuine stress incontinence \\
\hline Mean age (years) & $36.7 \pm 7.4$ & $37.2 \pm 6.9$ & $38.5 \pm 5.6$ & $37.2 \pm 7.1$ \\
Mean parity & $3.8 \pm 2.5$ & $4.2 \pm 1.6$ & $4.4 \pm 1.3$ & $4.1 \pm 1.6$ \\
Mode of delivery & & & & $36(90.0 \%)$ \\
Vaginal delivery & $1 \mathrm{l}(68.8 \%)$ & $32(88.9 \%)$ & $9(90.0 \%)$ & $0(0.0 \%)$ \\
Assisted vaginal delivery & $0(0.0 \%)$ & $0(0.0 \%)$ & $0(0.0 \%)$ & $4(10.0 \%)$ \\
Cesarean section & $5(31.2 \%)$ & $4(11.1 \%)$ & $1(10.0 \%)$ & 40 \\
Total & 16 & 36 & 10 & 0.985 \\
$\chi^{2} P$ value & 0.001 & 0.959 & 1.00 & $16(40.0 \%)$ \\
Carrying heavy load & & & & $24(60.0 \%)$ \\
Yes & $8(50.0 \%)$ & $19(52.8 \%)$ & $6(60.0 \%)$ & 40 \\
No & $8(50.0 \%)$ & $17(47.2 \%)$ & $4(40.0 \%)$ & 0.131 \\
Total & 16 & 36 & 10 & 0.034 \\
$\chi^{2} P$ value & 0.091 & 0.003 & &
\end{tabular}

of delivery is also a significant factor in the occurrence of urinary incontinence in this study.

The attitudes of these women with regard to seeking help was poor, as shown by the $0 \%$ consultation rate. This is the worst rate compared to other studies, ${ }^{13,15}$ although the likelihood of hospital consultation is low even in studies from developed countries like Spain (24\%), ${ }^{13}$ Germany (25\%), ${ }^{13}$ France (33\%), ${ }^{13}$ and Pennsylvania, US (25.5\%). ${ }^{15}$ The dismal help-seeking attitude of women with urinary leakage may be partly due to ignorance and partly due to the non-incapacitating nature of the condition.

In conclusion, it is obvious from this study that urinary leakage is a common problem among women of reproductive age in this part of the world, and those affected do not seek medical attention. This explains why it is considered a rare condition. The high prevalence calls for further evaluation, including its impact on quality of life. It is recommended that women should be encouraged to report any urinary leakage for possible treatment to improve their quality of life.

\section{Disclosure}

The authors report no conflicts of interest in this work.

\section{References}

1. Tsui AO, Grange AA, Ahmed S. The role of delayed childbearing in the prevention of obstetric fistulas. Int J Gynecol Obstet. 2007;99 Suppl 1: S98-S107.

2. Muleta M. Obstetric fistula in developing countries: a review article. J Obstet Gynaecol Can. 2006;28(11):962-966.

3. Kelly J. Repair of obstetric fistula: a review from an overseas perspective. The Obstetrician \& Gynecologist. 2004;4:205-211.

4. Ijaiya MA, Rahman AG, Aboyeji AP, et al. Vesicovaginal fistula: a review of Nigerian experience. West Afr J Med. 2010;29(5):293-98.

5. Eliasson K, Northlander I, Mattsson E, Larson B, Hammarstrom M. Prevalence of urinary leakage in nulliparous women with respect to physical activity and micturition habits. Int Urogynecol J. 2004;15(3): 149-153.
6. Shaw C, Gupta RD, Bushnell DM, et al. The extent and severity of urinary incontinence among women in UK waiting room. Fam pract. 2006;23(5):497-506.

7. Oliphant SS, Wang L, Bunker CH, Lowder JL. Trends in stress urinary incontinence in patient procedures in the United States, 1979-2004. Am J Obstet Gynecol. 2009;200:521. e1-e6.

8. Townsend MK, Curhan GC, Resnick NM, Grodstein F. The incidence of urinary incontinence across Asian, black and, white women in the United States. Am J Obstet Gynecol. Apr 2010;202(4):378. e1-e7. Epub December 29, 2009.

9. Araoye MO. Sample size determination. Research Methodology with Statistics for Health and Social Sciences. 1st ed. Nigeria: Nathadex Pub; 2003:115-121.

10. Vassallo B, Karram M. Urethral sphincter incontinence (Urodynamic stress incontinence). In: Shaw RW, Soutter WP, Stanton SL, editors. Gynecology. 3rd ed. China: Elsevier Science Ltd; 2003; 769-783.

11. Kelleher CJ, Cardozo LD, Khuller V, Salvatore S. A new questionnaire to assess the quality of life of urinary incontinent women. Br J Obstet Gynecol. 1997;104(12):1374-1379.

12. Hunskaar S, Arnold EP, Burgio K, Diokao AC, Horzog AG, Mallett VT. Epidemiology and natural history of urinary incontinence. Int Urogynecol J. 2000;11(5):301-319.

13. Hunskaar S, Lose G, Sykes D, Voss S. The prevalence of urinary incontinence in women in four European countries. BJU Int. 2004;93(3): 324-330.

14. Jolleys JV. Reported prevalence of urinary incontinence in women in a general practice. Br Med J. 1988;296(6632):1300-1302.

15. Burgio KL, Mattews KA, Engel BT. Prevalence, incidence and correlates of urinary incontinence in healthy middle-aged women. J Urol. 1991;146(5):1255-1259.

16. Rubens BS, Tissot WD, Diokno AC. Epidemiology: USA. In: Cardozo L, Staskin D, editors. Textbook of Female Urology and Urogynecology. Vol. 1. 2nd ed. London, UK: Informa Healthcare Ltd; 2006: $13-22$.

17. McGrother CW, Donaldson MMK, Shaw C, et al. Storage symptoms of the bladder: Prevalence, incidence and need for services in the UK. BJU Int. 2004;93(6):763-769.

18. Lewicky-Gaupp C, Brincat C, Trowbridge ER, et al. Racial differences in bother for women with urinary incontinence in the Establishing the Prevalence of Incontinence (EPI) study. Am J Obstet Gynecol. 2009; 201(5):510. e1-e6.

19. Thomas TM, Plymat KR, Blannin J, Meade TW. Prevalence of urinary incontinence. Br Med J. 1980;281(6250):1243. 


\section{Appendix \\ Questionnaire}

Age:

Occupation:

Is your work related to carrying heavy loads (load that needs an assistant to get the load on your head)? Yes/No

No of births 1, 2, 3, 4, 5 and above

Mode of birth deliveries

Vaginal delivery

Assisted delivery

Cesarean delivery (operation)

Who conducted the delivery (ies)?

\section{Relatives}

Doctors

Nurse/midwife

Traditional birth attendant

Have you experienced urinary leakage in the past? Yes/No

If the answer to the above question is yes, answer the following:

a. Is the involuntary loss of urine twice or more a month? Yes/No

b. Does the leakage of urine occur after coughing, sneezing, lifting, or exercise? Yes/No

c. Do you experience leakage of urine, or do you unintentionally empty your bladder before getting to a toilet when you have the urge to urinate? Yes/No

d. Do you experience leakage of urine following urinary retention? Yes/No

e. Do you use sanitary pads due to your urinary leakage? Yes/No

f. Has urine leakage affected your ability to do household chores? Yes/No

g. Has urine leakage affected your participation in social activities outside the home? Yes/No

i. Have you visited a health facility for treatment? Yes/No

\section{Publish your work in this journal}

The International Journal of Women's Health is an international, peerreviewed open-access journal publishing original research, reports, reviews and commentaries on all aspects of women's healthcare including gynecology, obstetrics, and breast cancer. Subject areas include: Chronic conditions (migraine headaches, arthritis, osteoporosis);

\section{Dovepress}

Endocrine and autoimmune syndromes; Sexual and reproductive health; Psychological and psychosocial conditions. The manuscript management system is completely online and includes a very quick and fair peer-review system. Visit http://www.dovepress.com/ testimonials.php to read real quotes from published authors. 